\title{
Analysis of Oxygen - enriched Combustion Characteristics of Corn Stalk Mixed with Coal Gangue
}

Chang-zhong Song, Jiang-hui Wen, Xin-ying Shi, Shen Xin Liu Kun (Inner Mongolia University of Technology, Inner Mongolia, Hohhot, 010051, China)

Keywords: Coal gangue, corn stalk, combustion characteristics

Abstract. The combustion characteristics of corn stalk and coal gangue mixture (1:4, 2:3, 3:2,4:1) were studied by thermogravimetric analysis. By the data analysis to obtain its combustion characteristics peak fire index, index volatile, flammable index, comprehensive characteristic index and other characteristic parameters. The activation energy and frequency factor were obtained by kinetic analysis. Finally, the conclusion was drawn that the mixing ratio had a great influence on the combustion performance and the best blending ratio was 3:2.

\section{Introduction}

World energy agency has asserted, the most direct impact on the Earth's habitat for human habitation is the carbon dioxide in the atmosphere. The increase in atmospheric concentrations of greenhouse gases (mainly $\mathrm{CO}_{2}$ ) is a major cause of global warming and extreme weather events. Therefore, it is necessary to further reduce the emission amount of the greenhouse gas $\mathrm{CO}_{2}$, its emission reductions have been extensively studied at home and abroad. More striking is the $\mathrm{O}_{2} / \mathrm{CO}_{2}$ cycle combustion, using pure oxygen and flue gas recirculation of pulverized coal combustion technology, the main features of this combustion method are the usage of pure oxygen for direct combustion with coal, and the introduction of flue gas recirculation. The $\mathrm{CO}_{2}$ in the flue gas replaces the nitrogen in the combustion air, thereby reducing the combustion chamber temperature, and ultimately make the exhaust $\mathrm{CO}_{2}$ concentration greatly increased $(90 \%) . \mathrm{CO}_{2}$ can be used and processed without separation, thereby effectively reducing $\mathrm{CO}_{2}$ emissions to the atmosphere, at the same time, the flue gas recirculation makes the exhaust smoke of the combustion device greatly reduced (only the traditional way of 1/5). Thus the boiler thermal efficiency can be improved significantly compared to different coal to draw conclusions: with the same input heat as a prerequisite. The heat flux density and the furnace temperature will be slightly increased at an $\mathrm{O} 2$ concentration of $35 \%$, it can be very flexible control of heat transfer and furnace temperature by changing the content of $\mathrm{O}_{2}$ in the recycled flue gas so that coal more adaptable. This is also $\mathrm{O}_{2} / \mathrm{CO}_{2}$ combustion technology used in coal-fired power plants in a major advantage. Coal is the main fossil energy in China, it is also the need of the times to carry out research on $\mathrm{CO} 2$ emission reduction of coal combustion. The formation of a large number of waste dump in mines taking up a lot of land, serious pollution of the environment; and high efficiency, low pollution utilization will save energy, environmental protection, having a high social and economic benefits. The coal gangue has the characteristics of low volatility, high ash content, low calorific value and difficult to burn, but the 
biomass has the characteristics of high volatile matter, low ash content and low calorific value per unit mass. Because the amount of volatile matter will affect the ignition performance of combustion, combustion calorific value depends on the number of combustion flammable content. Biomass with higher volatile content and combustion of coal gangue with fixed carbon content in $\mathrm{O}_{2} / \mathrm{CO}_{2}$ atmosphere will make the energy usage rationally.

\section{Experimental}

\section{Materials}

Experiments using corn stalk biomass and coal gangue Ximeng as experimental material, take 180-200 mesh coal gangue and 100-120 purpose biomass, The SDCHN series elemental analyzer and SDLA718 were used to determine the corn stalk and coal gangue respectively. The elemental analysis and industrial analysis are shown in Table 1.

Table 1 Proximate analysis and ultimate analysis of pure sample

\begin{tabular}{lccccccccc}
\hline & \multicolumn{4}{c}{ Proximate analysis } & \multicolumn{7}{c}{ ultimate analysis } \\
& Mad & Ad & Vd & FCd & C & H & O & N & S \\
\hline Corn stalks & 1.93 & 8.63 & 72.74 & 18.10 & 58.37 & 3.44 & 37.85 & 0.87 & 0.12 \\
Coal Gangue & 0.58 & 52.50 & 12.56 & 34.42 & 44.85 & 5.93 & 6.18 & 1.19 & 0.11 \\
\hline
\end{tabular}

\section{Experimental apparatus and methods}

In this paper, the Setys Evo synchronous thermogravimetric analyzer was used to separate biomass and coal gangue. Per sample weight of approximately $10 \mathrm{mg}$, using Al2O3 crucible material. High purity argon was used as the shielding gas. The combustion test was carried out under $\mathrm{O}_{2} / \mathrm{CO}_{2}(\mathrm{O} 2$ content $40 \%)$ atmosphere at a flow rate of $30 \mathrm{~mL} / \mathrm{min}$ and the furnace temperature was increased from ambient temperature to $1000{ }^{\circ} \mathrm{C}$ at the speed of $20 \mathrm{~K} \cdot \mathrm{min}^{-1}$.

\section{Results and Analysis}

Curve analysis
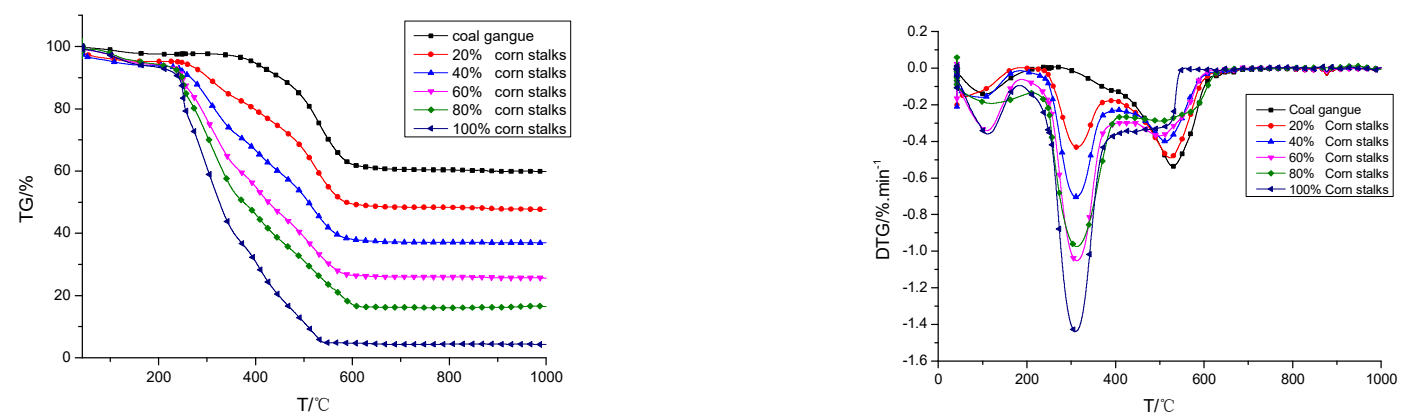


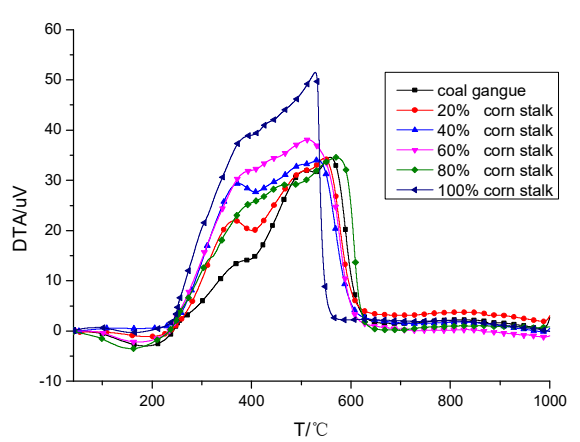

Fig. 1. Combustion profiles of the blends

With the increase of corn stalk content in coal gangue, the weight loss curve of the combustion process will gradually decrease, and the weight loss curve of mixed sample is between the two single combustion samples. With the addition of corn stalks in coal gangue, the weight loss rate curve DTG from the original two weight loss peak into three weightlessness peak. Where the zero-weight peak is due to the evaporation of moisture caused by the small weight loss. The first weightlessness peak is mainly due to the precipitation of volatile matter or the weight loss due to combustion exotherm. The second weightlessness peak is mainly due to the decomposition of fixed carbon or combustion-induced weight loss. Because corn stalks in a large number of volatile, coal gangue corn stalk was added to increase weight loss peak devolatilization or weightlessness peak combustion caused by heat. The addition of coal gangue in corn stalks prolonged the burning time and accompanied the obvious weight loss phenomenon. The phenomenon of the second weightlessness peak was obvious due to the fixed carbon pyrolysis and combustion in coal gangue. Wherein the first peak of the most obvious weight loss, mixed sample in the first $60 \%$ of the biomass peak maximum weight loss, weight loss of $20 \%$ of the biomass of the second largest peak. Seen by the DTA curve, DTA peak mixed sample ranged from a single peak between the two samples, and the peak temperature ranging between the two single samples, $60 \%$ of raw material mixed sample exothermic peak maximum, exothermic most.

\section{Combustion characteristic parameters DTG, DTA peak}

From the combustion curve can be obtained as follows peak table2

Table 2 The peak of DTG and DTA

\begin{tabular}{|c|c|c|c|c|c|c|c|c|}
\hline \multirow{2}{*}{ sample } & \multicolumn{4}{|c|}{ DTG peak } & \multicolumn{4}{|c|}{ DTA peak } \\
\hline & first peak & Peak temperature & $\begin{array}{c}\text { Second } \\
\text { peak }\end{array}$ & Peak temperature & first peak & Peak temperature & $\begin{array}{c}\text { Second } \\
\text { peak }\end{array}$ & Peak temperature \\
\hline Coal Gangue & & & 0.5363 & 530 & & & 34.5508 & 559 \\
\hline $\begin{array}{l}\text { Corn stalks: Coal } \\
\text { Gangue }=1: 4\end{array}$ & 0.43182 & 314 & 0.4898 & 524 & 21.9076 & 369 & 34.1982 & 550 \\
\hline $\begin{array}{l}\text { Corn stalks: Coal } \\
\text { Gangue }=2: 3\end{array}$ & 0.70356 & 311 & 0.4005 & 512 & 29.3739 & 375 & 34.0236 & 533 \\
\hline $\begin{array}{l}\text { Corn stalks: Coal } \\
\text { Gangue }=3: 2\end{array}$ & 1.05163 & 313 & 0.3691 & 502 & 31.8289 & 392 & 38.0984 & 512 \\
\hline $\begin{array}{l}\text { Corn stalks: Coal } \\
\text { Gangue }=4: 1\end{array}$ & 0.9749 & 315 & 0.2579 & 553 & 30.4595 & 392 & 34.5455 & 572 \\
\hline Corn stalks & 1.43819 & 310 & 0.3164 & 514 & 38.7941 & 390 & 51.4053 & 526 \\
\hline
\end{tabular}



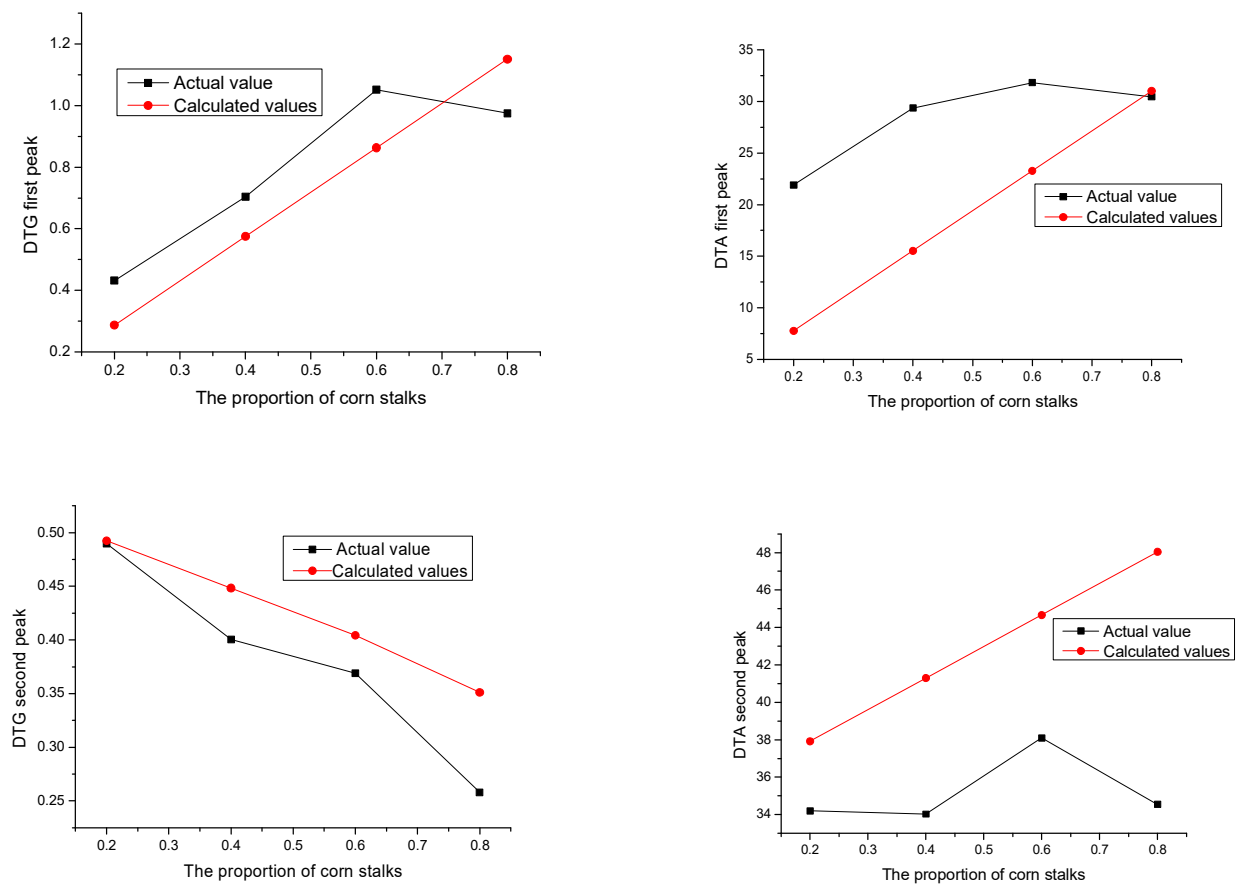

Fig. 2. Actual peak and calculated peak contrast curves

By comparing DTG and DTA, it is possible to determine whether DTG is a peak due to a change in weight or a peak due to a change in heat. The weight loss peak of DTG represents the maximum value of the weight loss rate, and the peak of DTA represents the maximum value (i.e., burning rate) of the combustion heat release rate. The first weight loss peak is mainly due to the precipitation and combustion of volatile matter, and the second weight loss peak is mainly due to the cracking and combustion of fixed carbon. Since the coal gangue is a coal with low volatile content, the first peak is not very obvious. DTA peak temperature is greater than the temperature corresponding to a peak corresponding to the DTG, the peak of the DTG weight variation is caused largely.

With a blend of coal gangue corn stalk mixed sample DTG peaks are higher than the first single gangue, indicating corn stalk blends to improve the characteristics of volatile precipitation, where $60 \%$ of the biomass sample weightlessness peak maximum. Devolatilization stage, mixing of volatile precipitation are promoted only $80 \%$ of biomass devolatilization inhibition, it is possible to analyze the volatile temperature and a small amount of volatile coal gangue analyze the correspondence consistent temperature, so the biomass devolatilization restrained, $60 \%$ of the biomass samples to promote the most significant effect. Mixing a sample of the volatile combustion play a promote role,only $80 \%$ of the biomass volatile combustion is not affected, because $80 \%$ of volatile analysis of a small amount of oxygen consumption is not very much, so the effect is not obvious. Mixing a sample of the cracking process are fixed carbon inhibition may biomass sample contains large amounts of inorganic chemical reaction cleavage intermediates fixed carbon, $80 \%$ of the biomass 
samples showed the most obvious inhibitory effect on carbon fixation. Fixed carbon combustion process in the combustion process are Inhibition of all fixed carbon in the sample, $60 \%$ of the minimum inhibitory biomass samples.

\section{Combustion characteristics index}

The use of thermal analysis TG-DTG curves obtained pulverized coal combustion temperatures, thereby determining its ignition temperature Ti. The combustion peak temperature is the peak temperature corresponding to the highest combustion rate, and the burnout temperature is the temperature $\mathrm{T}_{\mathrm{f}}$ corresponding to the conversion rate of $98 \%$. Obtained by the characteristic temperature curve and combustion characteristics of the specific values of the following parameters in table 3:

Table 3 Characteristics of the sample index

\begin{tabular}{lcccccc}
\hline sample & DTGmax & DTGmean & Di *10 & $\mathrm{C}^{*} 10^{6}$ & $\mathrm{D} * 10^{6}$ & $\mathrm{~S}^{*} 10^{10}$ \\
\hline Coal Gangue & 0.5354 & 0.06757 & 1.6342 & 2.6799 & 8.6191 & 2.4704 \\
Corn stalks: Coal Gangue =1: 4 & 0.4899 & 0.0894 & 2.7821 & 7.0291 & 7.6011 & 9.4213 \\
Corn stalks: Coal Gangue =2: 3 & 0.7035 & 0.10019 & 4.7039 & 11.626 & 27.588 & 19.158 \\
Corn stalks: Coal Gangue =3: 2 & 1.0514 & 0.12679 & 7.7007 & 19.038 & 39.394 & 41.548 \\
Corn stalks: Coal Gangue =4: 1 & 0.9749 & 0.13232 & 7.0021 & 17.211 & 28.0076 & 38.9289 \\
Corn stalks & 1.4381 & 0.14709 & 11.7538 & 27.187 & 48.835 & 75.1678 \\
\hline
\end{tabular}

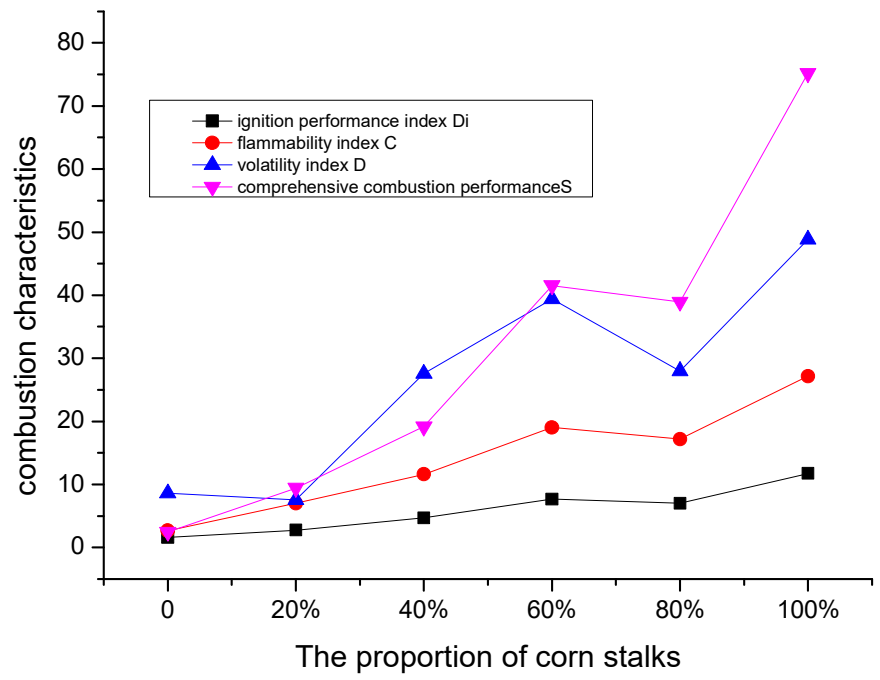

Fig. 3. Combustion characteristic parameter curve

It can be seen from the combustion characteristic parameter that the mixed sample shows the tre nd of increasing first and then decreasing of which $60 \%$ of the biomass samples obtained the most va lue. From the volatile index, the volatiles index of $20 \%$ biomass sample is smaller than that of coal $\mathrm{g}$ angue. So that it is not as long as the coal gangue in the corn stalks will definitely enhance the volati 
lity of the sample analysis of the characteristics. From the peak temperature shows that $20 \%$ of the bi omass of coal gangue on the corn stalk in the volatile matter precipitation is to promote the role of th e combustion of volatile components is inhibited. The same $60 \%$ of the maximum value also shows $t$ he coal gangue mixed with corn stalks, nor is more corn stalks on the volatilization of more features $\mathrm{t}$ o promote the stronger role. In the mixed sample, the performance of the $60 \%$ biomass sample was th e best, the best blending ratio of the blending ratio sample is described.

\section{Kinetics Analysis}

The kinetic analysis shows that the rate of change of the mass of the raw material vari es with the temperature, which also revealed the laws of physical and chemical changes in th e combustion process, the processes and mechanisms of various reactions were obtained and $\mathrm{t}$ he relevant kinetic parameters were determined, so as to provide a theoretical basis for the $\mathrm{s}$ tudy.The volatilization process of coal gangue and biomass is the thermal decomposition reac tion process, having a thermal decomposition reaction of the basic features. For the decompo sition reaction of the solid, the reaction rate is generally expressed as

$$
\frac{d a}{d t}=k f(a)
$$

Where $a$ is the conversion rate, $t$ is the time, $k$ is the chemical reaction rate constant, a nd $f(a)$ is a function of the conversion rate, which is determined by the reaction mechanism.

According to Arrheneius equation:

$$
k=A \exp \left(-\frac{E}{R T}\right)
$$

Where $E$ is the activation energy $((\mathrm{KJ} / \mathrm{mol})), R$ is ideal gas constant $(8.314 \mathrm{~J} /(\mathrm{mol} \bullet \mathrm{K})), T$ is Thermodynamic temperature(K).

Substituting equation (3-2) into equation (3-1) yields:

$$
\frac{d a}{d t}=A \exp \left(-\frac{E}{R T}\right) f(a)
$$

Integral to (3-3), $\quad g(a)=\int_{0}^{a} \frac{d(a)}{f(a)}$, so:

$$
g(a)=A \int_{T_{0}}^{T} \exp \left(-\frac{E}{R T}\right) d t
$$

In the case of constant heating rate:

$$
\beta=\frac{d T}{d t}
$$

By (3-4), (3-5) to give finishing:

$$
g(a)=\frac{A}{\beta} \int_{T_{0}}^{T} \exp \left(-\frac{E}{R T}\right) d T
$$

To (3-6) integral consolidation, while taking the logarithm on both sides was:

$$
\ln \left[\frac{g(a)}{T^{2}}\right]=\ln \left\{\frac{A R}{\beta E}\left[1-\frac{2 R T}{E}\right]\right\}-\frac{E}{R T}
$$


Since E / RT»1, at this time (3-7) can be simplified:

$$
\ln \left[\frac{g(a)}{T^{2}}\right]=\ln \frac{A R}{\beta E}-\frac{E}{R T}
$$

If this formula as a function of the relationship between $\ln \left[\mathrm{g}(\mathrm{a}) / \mathrm{T}^{2}\right]$ and $1 / \mathrm{T}$. Well, this is a to $-\mathrm{E} / \mathrm{R}$ is the slope, a function of the intercept is $\ln (\mathrm{AR} / \beta \mathrm{E})$.By doing maps, linear fit, find qualified expression.So by the same relationship between $\ln \left[\mathrm{g}(\mathrm{a}) / \mathrm{T}^{2}\right]$ and $1 / \mathrm{T}$ obtained by the slope and intercept, and then get the activation energy $\mathrm{E}$ and frequency factor $\mathrm{A}$, as shown in table 5 below.

Activation energy refers to the difference value between the average energy of the activated molecule and the average energy of the reaction molecule. The smaller the activation energy is, the more likely the reaction occurs. The frequency factor $\mathrm{A}$ is a parameter related to the rate at which the activated molecule is converted to the product. By fitting the pyrolysis curve, the correlation coefficient between the pyrolysis curve and the fitting curve is close to 1 , which indicates that the linear fitting degree is better.The analysis of pyrolysis curve usually adopt the method of segmentation because of its irregular.

According to different kinetic model $g$ (a), the kinetics of coal pyrolysis is calculated and the best linear correlation coefficient is obtained. According to the comparison calculation, the pyrolysis process of coal gangue and biomass is in accordance with first order reaction ,ie $g(a)=-\ln (1-a)$, and eventually calculate $\mathrm{E}$ and A.

Table 4 Reaction-kinetic parameters

\begin{tabular}{lcccc}
\hline sample & temperature range $/{ }^{\circ} \mathrm{C}$ & $\begin{array}{l}\text { Correlation } \\
\text { coefficient }\end{array}$ & activation energyE/KJ.mol ${ }^{-1}$ & Frequency factorA $/ \mathrm{min}^{-1}$ \\
\hline Coal Gangue & & & \\
Corn stalks: Coal Gangue =1: 4 & $226-392$ & 0.91603 & 3242 & $9.29 \times 10^{8}$ \\
Corn stalks: Coal Gangue =2: 3 & $208-407$ & 0.92618 & 3998 & $5.94 \times 10^{8}$ \\
Corn stalks: Coal Gangue =3: 2 & $193-416$ & 0.92181 & 4871 & $4.38 \times 10^{8}$ \\
Corn stalks: Coal Gangue =4: 1 & $212-410$ & 0.93134 & 6260 & $2.99 \times 10^{8}$ \\
Corn stalks & $186-398$ & 0.96675 & 5264 & $2.79 \times 10^{8}$ \\
\hline
\end{tabular}

Table 5 Reaction-kinetic parameters

\begin{tabular}{lcccc}
\hline sample & temperature range ${ }^{\circ} \mathrm{C}$ & $\begin{array}{l}\text { Correlation } \\
\text { coefficient }\end{array}$ & activation energyE/KJ.mol ${ }^{-1}$ & Frequency factorA $/ \mathrm{min}^{-1}$ \\
\hline Coal Gangue & $250-685$ & 0.96919 & 14443 & $1.137 \times 10^{9}$ \\
Corn stalks: Coal Gangue =1: 4 & $392-687$ & 0.90986 & 10976 & $3.83 \times 10^{8}$ \\
Corn stalks: Coal Gangue =2: 3 & $407-645$ & 0.90985 & 9451 & $3.54 \times 10^{8}$ \\
Corn stalks: Coal Gangue =3: 2 & $416-663$ & 0.90297 & 8241 & $3.52 \times 10^{8}$ \\
Corn stalks: Coal Gangue =4: 1 & $410-648$ & 0.93497 & 19977 & $7.51 \times 10^{7}$ \\
Corn stalks & $398-575$ & 0.9556 & 20726 & $3.36 \times 10^{7}$ \\
\hline
\end{tabular}

The activation energy is non-activated molecules into energy activated molecules absorbed, the greater the activation energy, indicating that more needs to absorb energy generating reaction, the 
reaction harder, more difficult ignition activation energy of greater substance, namely fire poor performance. The activation energy of coal gangue can be reduced by mixing corn stalk with coal gangue.

The first phase of the activation energy of the reaction $E_{14}<E_{23}<E_{32}<E_{41}$, the results show that the activation energy of coal gangue increases with the increase of corn stalk content, and the fire becomes more and more difficult. The second reaction stage, mixing the sample $60 \%$ of the minimum value of the activation energy of the biomass samples, indicating that the blend more easily than the lower fixed carbon reaction stages, activation order of E32<E23<E14<E41.The activation energy does not decrease with the increase or decrease of a substance in the mixture, description fixed carbon ignition stage is more complicated, both by the effects of chemical substances contained in. With the increase in corn stalk gangue content of the corresponding frequency factor showed a decreasing trend, effectively reducing the number of collisions.

\section{Conclusion}

The usage of thermal analysis of corn stalk and gangue 1:4,2:3,3:2,4:1 were mixed sample combustion analysis, some of the characteristics of combustion mixing and combustion kinetics equation and parameter give it.

(1) After blending coal gangue corn stalk, the reaction increase devolatilization and combustion stage. $60 \%$ of the biomass samples were found to be the strongest in devolatilization and combustion stage. Fixed carbon pyrolysis and combustion characteristics of the sample stage $20 \%$ of the biomass of the strongest. Exothermic peak in total, $60 \%$ of the maximum heat release of biomass samples.

(2) DTG and DTA peak that comparative analysis, DTG peak weight loss is mainly due to the change in weight caused. After the sample was mixed, the volatilization and combustion phases were all promoted, except that $80 \%$ of the biomass samples were inhibited during the volatilization analysis, of which $60 \%$ of the biomass samples in the volatile analysis and combustion phase of the most significant role in promoting. The inhibition of carbon fixation in the pyrolysis and combustion phases of the fixed carbon could be attributed to the inhibition of the immobilized carbon cracking by the inorganic salts in the corn stalk, $60 \%$ inhibition of the biomass samples minimum and $80 \%$ of the biomass samples strongest inhibition. From the combustion characteristics of the index, $60 \%$ of the index value of the largest biomass samples the strongest performance, and the mixed sample combustion characteristic exponents are very greatly improved compared with two kinds of single samples.

(3) From the kinetic analysis, it can be seen that the activation energy increases with the increase of the corn stalk content in the combustion phase, and the ignition is more difficult. And that is 
both more complex fixed carbon contained in the ignition phase of the impact of chemicals. With the increase in the frequency factor gangue content of corn stalk and continue to decrease.

\section{Acknowledgements}

Project funding: National Natural Science Foundation Project

Project ID: 51466010

\section{References}

[1] Marisamy Muthuraman. Characteristics of co-combustion and kinetic study on hydrothermally treated municipal solid waste with different rank coals: A thermogravimetric analysis[J], Applied Energy, 2010, 87: 141-148.

[2] Li Xiang-guo.Thermogravimetric analysis of the co-combustion of theblends with high ash coal and waste tyres[J], Thermochimica Acta, 2006, 441: 79-83.

[3] M. Varol. Investigation of co-combustion characteristics of low quality lignite coals andbiomass with thermogravimetric analysis[J], Thermochimica Acta, 2010, 510: 195-201.

[4] M. Otero. Co-combustion of different sewage sludge and coal: A non-isothermal thermogravimetric kinetic analysis[J], Bioresource Technology , 2008, 99: 6311-6319.

[5] M. Varol. Investigation of co-combustion characteristics of low quality lignite coals and biomass with thermogravimetric analysis[J], Thermochimica Acta , 2010, 510: 195-201.

[6] Marisamy Muthuraman. Characteristics of co-combustion and kinetic study on hydrothermally treated municipal solid waste with different rank coals: A thermogravimetric analysis[J], Applied Energy , 2010, 87: 141-148.

[7] Xiao Hanmin. Co-combustion kinetics of sewage sludge with coal and coal gangue under different atmospheres[J] , Energy Conversion and Management , 2010, 51: 1976-1980.

[8] Li Xiang-guo. Thermogravimetric analysis of the co-combustion of the blends with high ash coal and waste tyres[J], Thermochimica Acta , 2006, 441: 79-83.

[9] S.G. Sahu. Thermogravimetric assessment of combustion characteristics of blends of a coal with different biomass chars[J], Fuel Processing Technology , 2010, 91: 369-378.

[10] X.G. Li. Thermogravimetric investigation on co-combustion characteristics of tobacco residue and high-ash anthracite coal[J], Bioresource Technology ，2011，102: 9783-9787.

[11] Zhengang Liu. Thermogravimetric investigation of hydrochar-lignite co-combustion[J], Bioresource Technology, 2012, 123: 646-652.

[12] X.G. Li. Thermogravimetric investigation on co-combustion characteristics of tobacco residue and high-ash anthracite coal[J], Bioresource Technology, 2011, 102: 9783-9787.

[13] Li Xiang-guo. Thermogravimetric analysis of the co-combustion of the blends with high ash coal and waste tyres $[\mathrm{J}]$, Thermochimica Acta, 2006, 441: 70-83.

[14] Liao Yanfen. Thermogravimetric analysis of the co-combustion of coal and paper mill sludge [J], Applied Energy, 2010, 87: 3526-3532.

[15] M. Oteroa,b. Co-combustion of different sewage sludge and coal: A non-isothermal thermogravimetric kinetic analysis [J], Bioresource Technology ,2008, 99: 6311-6319.

[16] Xiao Hanmin. Co-combustion kinetics of sewage sludge with coal and coal gangue under different atmospheres [J], Energy Conversion and Management ,2010, 51: 1976-1980.

[17] S.G. Sahua. Thermogravimetric assessment of combustion characteristics of blends of a coal with different biomass chars [J], Fuel Processing Technology ,2010, 91: 369-378. 
[18] M.V. Gil. Thermal behaviour and kinetics of coal/biomass blends during co-combustion[J], Bioresource Technology,2010,101: 5601-5608.

[19] M. Varol a. Investigation of co-combustion characteristics of low quality lignite coals and biomass with thermogravimetric analysis[J], Thermochimica Acta ,2010, 510: 195-201.

[20] Zhengang Liu. Thermogravimetric investigation of hydrochar-lignite co-combustion[J], Bioresource Technology ,2012,123: 646-652.

Corresponding author. Tel. +8613614711033; E-mail address: songchzh@imut.edu.cn . 